\title{
A INCLUSÃO DO ALUNO COM SÍNDROME DE DOWN: UM ESTUDO SOBRE A SITUAÇÃO ESCOLAR NO ENSINO FUNDAMENTAL E MÉDIO DA CIDADE DE ARARAQUARA - SP
}

\author{
Márcia DUARTE ${ }^{1}$ \\ Luci Pastor MANZOLI ${ }^{2}$
}

\begin{abstract}
RESUMO: O presente estudo teve por objetivo conhecer a situação escolar dos alunos com síndrome de Down que frequentavam o Ensino Fundamental e Médio das escolas da rede pública e particular da cidade de Araraquara - SP, no que se refere aos conteúdos correspondentes às séries que estão freqüentando. Para tanto, foi realizado um levantamento do número desses alunos nessas redes de ensino no início do ano letivo de 2006. Esse levantamento mostrou que havia 7 alunos, sendo 5 da rede estadual da $2^{\mathrm{a}}, 3^{\mathrm{a}}, 4^{\mathrm{a}}, 5^{\mathrm{a}}$ e $6^{\mathrm{a}}$ séries do Ensino Fundamental, sendo um do sexo masculino e quatro do feminino, com idades de 14 a 21 anos e dois da rede particular na $5^{\mathrm{a}}$ série do e outro no $2^{\circ}$ ano do Ensino Médio, ambos do sexo masculino com 17 e 18 anos, respectivamente. Para conhecer a trajetória escolar desses alunos, bem como a situação na série que estavam freqüentando, foram realizadas entrevistas com os pais e professores. Os resultados apontaram que esses alunos freqüentaram as classes especiais por um período de 3 a 15 anos para depois serem matriculados no ensino regular, com exceção de um, que não freqüentou essa classe. A pesquisa mostrou que esses alunos necessitam de um maior tempo para a realização das tarefas, ensino individualizado, adequação curricular, bem como mudança na forma de transmitir os conteúdos e de dosar mais a quantidade das atividades para evitar o cansaço.
\end{abstract}

PALAVRAS-CHAVE: Síndrome de Down. Professor. Escolas do ensino regular. Inclusão.

A disseminação do modelo de Educação Inclusiva, nomeadamente pela inclusão de alunos com necessidades educacionais especiais na escola regular, origina novos desafios para as escolas. Considerando que inclusão implica em mudanças no ambiente escolar visando oportunidades iguais para todos os alunos, oportunidades educacionais - formais e sociais, este estudo mostra alguns caminhos de reorganização necessários à escola para a educação de alunos com síndrome de Down, ou em outras palavras, caminhos para a escola se tornar inclusiva.

A inclusão escolar é uma possibilidade de convívio destes alunos em ambientes das classes regulares, onde não permanecerão mais isolados, mas, sim, interagindo com outros alunos em um mesmo grupo.

Diante dos documentos de grande relevância, entre os quais: a Conferência Mundial sobre Educação para Todos (1990), em Jontiem, na Tailândia, Conferência Mundial sobre

\footnotetext{
1 Faculdade São Luiz. Jaboticabal - SP - Brasil. 14870-000.

2 .UNESP - Universidade Estadual Paulista. Faculdade de Ciências e Letras - Departamento de Didática. Araraquara - SP - Brasil. 14800-901 - ozilu@yahoo.com.br
} 
Necessidades Educativas Especiais, em Salamanca, na Espanha (1994) e a Lei de Diretrizes e Bases - LDB 9.394/96, o paradigma inclusivo materializou-se e adentrou as discussões no Brasil e veio ganhando espaço com base no pressuposto de que a educação de qualidade é direito de todos. A partir de então, foi estabelecido que as pessoas com deficiência tivessem garantida a freqüência no ensino regular, pois toda pessoa tem direito ao acesso e permanência na escola.

A Política de Educação Especial na perspectiva da Educação Inclusiva destaca a trajetória da educação especial e sua evolução a partir das experiências educacionais que vêm acontecendo no Brasil, visando à construção de sistemas educacionais inclusivos. Este documento consolida o pensamento de vários segmentos de pessoas com deficiência e vem, principalmente, atender a diversos documentos nacionais e internacionais que combatem qualquer forma de discriminação contra essas pessoas.

A partir daí, as discussões sobre a educação inclusiva foram fortalecendo-se, e as escolas passaram a receber as pessoas com diversas deficiências: física, visual, auditiva e mental, incluindo aquelas com síndrome de Down. A inclusão encontrou solidez com o trabalho de pesquisadores da área educacional e com as experiências positivas de famílias que optaram por matricular seus filhos em escolas do ensino regular.

Os estudos a respeito da deficiência mental mostram que a trajetória através dos tempos, em relação à pessoa com síndrome de Down, é permeada por mitos, preconceitos e segregação. Por suas características físicas, como olhos arredondados e puxados para cima, baixa estatura, orelhas e mãos pequenas, eram chamados de mongolóides, devido a algumas semelhanças físicas com os povos da Mongólia.

Duarte (2003, p.21) retoma as descrições de Schwartzman (1999) quanto às diferentes denominações da síndrome de Down, isto é: “[...] imbecilidade mongolóide, idiotia mongolóide, cretinismo furfáceo, acromicria congênita, criança mal-acabada e criança inacabada”.

O objetivo com este estudo não foi apenas produzir dados descritivos, mas verificar que possibilidades, alternativas, caminhos, entre outras interpretações, poderiam ser produzidas diante da situação escolar dos alunos com síndrome de Down na escola.

A educação desses alunos, até bem pouco tempo, ocorria de forma exclusivamente segregada, em classes e escolas especiais, sob a responsabilidade de professores especializados. Entretanto, a educação vem sofrendo inúmeras modificações com as influências vividas em cada período histórico, transformando, assim, as escolas, instituição encarregada da educação formal de crianças, jovens e adultos. É ela que, por meio da prática 
pedagógica, atua como organizadora e transmissora de conhecimentos na trajetória de vida das pessoas, criando condições de inserção no meio social.

As políticas públicas garantem o acesso de todos os alunos à escola. Apesar disso, muitos não têm sua aprendizagem garantida e estão chegando à idade adulta sem conseguir ler, escrever, interpretar e compreender a escrita. A construção de uma sociedade inclusiva passou a ser um ponto fundamental para o desenvolvimento da democracia, sendo a educação inclusiva parte fundamental desse processo.

Pressupõe-se, então, que a escola deveria ser uma instituição socialmente responsável não só pela democratização do acesso ao conhecimento, mas também para desempenhar o papel de responder pelo pleno desenvolvimento de seus alunos, objetivando sua inserção como cidadãos capazes de enfrentar desafios e serem respeitados dentro do contexto social. Esse é o maior desafio para a escola, hoje, que precisa modificar-se e aprender a conviver com dificuldades e diferentes níveis de aprendizagem escolar de seus alunos.

Mesmo trazendo este objetivo que necessita ser estendido a todos, percebe-se que a educação ainda acontece de um modo peculiar e que, durante sua trajetória, há uma boa parte de alunos ainda excluídos dessa realidade, como, por exemplo, os alunos que apresentam deficiência mental. Compreende-se que, para a escola cumprir a sua função, esta deva passar a incorporar projetos, assumindo a responsabilidade de trabalhar para a superação das deficiências, atendendo à diversidade a partir das necessidades dos alunos.

No caso da presente investigação, discute-se a situação escolar dos alunos com síndrome de Down que, até então, permaneciam isolados, à mercê do convívio educacional na rede regular de ensino, participando, muitas vezes, somente como coadjuvantes da escola, sem estarem propriamente incluídos. Os alunos com essa síndrome representam desafio e dificuldade para o professor, pois carregam características biológicas, físicas e cognitivas que tendem a incomodar e, muitas vezes, frustrar o trabalho dos professores.

Historicamente, foi sendo construída pela sociedade uma visão permeada por mitos, preconceitos e segregação em relação aos alunos com síndrome de Down. Conceitos de que esses alunos apresentam incapacidade intelectual, não tendo condições de aprendizagem e socialização dentro do contexto escolar.

O presente estudo visou a conhecer a situação escolar dos alunos com síndrome de Down que freqüentam o Ensino Fundamental e Médio das escolas da rede pública e particular da cidade de Araraquara - SP. Para tanto, foi necessário entrevistar os pais e os seus professores, sendo os primeiros, para traçar a trajetória escolar desses alunos, e os segundos, para conhecer a situação escolar dos mesmos diante da inclusão. Também se organizou um 
grupo de estudos com 5 alunos da rede pública, visando a aplicar atividades de leituras e interpretação de histórias e a escrita. Dessa forma, poder-se ia se compreender melhor as colocações a situação escolar desses alunos.

Participaram desta pesquisa sete alunos com síndrome de Down, sendo cinco da rede estadual, distribuídos nas seguintes séries: $2^{\mathrm{a}}, 3^{\mathrm{a}}, 4^{\mathrm{a}}, 5^{\mathrm{a}}$ e $6^{\mathrm{a}}$, sendo um do sexo masculino e quatro do sexo feminino, com idades variando de 14 a 21 anos e dois da rede particular, sendo um na $5^{\mathrm{a}}$ série do Ensino Fundamental e outro no $2^{\circ}$ ano do Ensino Médio, ambos do sexo masculino, com 17 e 18 anos de idade, totalizando sete alunos. Os alunos foram identificados por apelidos escolhidos por eles, mantendo o anonimato dos participantes da pesquisa (Nanda, Ana, Mila, Nilo, Nita, Zé e Nando). Participaram também quatorze professores da rede estadual e onze da rede particular, num total de vinte e cinco professores e também sete familiares, sendo um pai, quatro mães e duas avós.

O estudo foi desenvolvido em 7 escolas, sendo 5 do Ensino Fundamental da Rede Estadual e 2 da Rede Particular do Ensino Fundamental e Médio que possuíam alunos com síndrome de Down incluídos, e uma sala de aula de uma escola de inglês localizada no centro da cidade, que foi cedida pelo pai de uma aluna participante da pesquisa.

Conforme apontou a revisão bibliográfica, a síndrome de Down foi considerada, durante muitas décadas, como uma deficiência mental severa com prognóstico impreciso e negativo que implicou uma visão distorcida e pessimista sobre aqueles que apresentam essa alteração genética. À medida que novas pesquisas foram surgindo, verificou-se que existem pessoas com essa síndrome em que o atraso cognitivo é tão pequeno que se encontram no limite da normalidade, e outros em que a deficiência mental se manifesta com um grau mais comprometido; no entanto, é porque essa síndrome tem associada uma patologia de caráter neurológico ou porque o aluno se encontra isolado e privado de um contexto familiar e escolar rico em estimulações. Portanto fica evidente que muitos são os fatores que desencadeiam diferentes situações de aprendizagem escolar desses alunos e o professor deve conhecer a potencialidade de cada aluno com base em seu desenvolvimento.

Os dados apontaram que os alunos participantes deste estudo chegaram à escola regular, em sua grande maioria, com passagem pela classe especial e, nas escolas regulares.

Acredita-se que a classe especial, por não ter seriação e tampouco exigir avaliação para verificar a aprendizagem desses alunos, acabou tendo efeitos prejudiciais no processo de inclusão escolar, pois não proporcionou a base de conhecimento que um currículo de escola regular exige. 
Entre os alunos, somente Nando não está com defasagem idade/série, enquanto os demais estão com idades entre 14 e 21 anos freqüentando a $1^{\mathrm{a}}$ e $2^{\mathrm{a}}$ etapas do Ensino Fundamental, sendo que deveriam estar, no mínimo, cursando o Ensino Médio ou Superior. Além disso, Nilo e Nita perderam a seriação normal e da classe especial foram diretamente para a $4^{\text {a e }} 5^{\text {a }}$ série. Pergunta-se: "se uma pessoa considerada normal, tivesse sido colocada na mesma situação de Nilo e Nita, como estaria a situação escolar dela?” Esse é um assunto que precisa ser pesquisado.

Foi constatado no presente estudo que, embora esses alunos se saiam melhor na aprendizagem com mediação, estão sem esse apoio na escola, e alguns estão conseguindo equiparar-se a alguns colegas sem essa síndrome. E embora com dificuldades e "lentos”, estão em sala de aula e tendo progressos. Segundo Flórez e Troncoso (1994), a dificuldade para aprender não deve ser considerada como algo generalizável a todo tipo de aprendizagem.

Segundo Mazzotta (1989, p.4), o atendimento não deve dar-se “[...] em função das limitações, mas principalmente da capacidade de desenvolvimento e mudança do ser humano”.

Esta pesquisa possibilitou compreender a situação de aprendizagem escolar desses alunos e verificou os ganhos significativos não só no desenvolvimento social, mas também no cognitivo. O grupo de estudos proporcionou à pesquisadora conhecimento de como esses 5 alunos compreendem e interpretam as histórias lidas e escrevem histórias através de leitura realizada.

É interessante notar que os professores, os pais e a pesquisadora, observaram pontos comuns na situação de aprendizagem desses alunos, havendo a necessidade de utilizar mais tempo para a realização das tarefas, a necessidade de um ensino mais individualizado, a necessidade de adaptação curricular, os conteúdos dados devem ser transmitidos de forma dosada para evitar o cansaço e a mudança na forma de transmiti-los. Notou-se também a necessidade de estimulação e o uso de material concreto, pois conceitos abstratos tornam-se bastante difíceis para eles.

Os dados deste estudo mostraram que esses alunos com apoio de um mediador conseguem reter na memória as idéias que estão sendo passadas. As atividades que foram trabalhadas no grupo de estudos assumem formas atraentes e que despertam curiosidade e interesse dos alunos, diferentemente de disciplinas como Matemática, História, Geografia, Física, química e outras que são trabalhadas tradicionalmente. Além disso, para estabelecer esse contexto de atenção individualizada e diferenciada as classes devem ser compostas de menos de 38 alunos ou ter mais professores atuando. 
Nas atividades pedagógicas a que os participantes do grupo de estudos estiveram expostos, além do diálogo realizado com os alunos, foi proporcionado também um tempo maior, de duas horas, para a resolução das tarefas de escrita. Mesmo com a ajuda da pesquisadora, esse tempo não foi diminuído.

Relacionando os dados do grupo de estudos com os obtidos nas entrevistas dos professores, ficou evidente que, quando a pesquisadora fez uma revisão das atividades realizadas no dia anterior, os alunos se lembravam das atividades por si sós, dispondo de subsídios e autonomia para realizar corretamente a atividade solicitada. Com esse tipo de apoio, verificou-se que foram capazes de compreender e interpretar, desde que sejam oferecidas explicações individuais, diálogos e mais tempo para elaborarem o pensamento.

Ficou evidente a necessidade de se fazer, em todas as aulas, uma revisão de dos assuntos trabalhados no dia anterior para que se começasse um novo assunto. É de suma importância realizar essa retomada, pois é difícil prever uma aprendizagem cumulativa para esses alunos.

Foi observado também que esses alunos apresentam características comuns entre si como a necessidade de um tempo maior para aprender as tarefas com apoio do material concreto, e a escrita com frases curtas, dentre outros. Isto não sela a potencialidade desses alunos, pois, se estimulados e assistidos de forma correta, poderão apresentar um bom desempenho.

Diante de cada ponto fraco apresentado pelos alunos, é preciso verificar o que poderá ser trabalhado para auxiliar nas dificuldades. Se a aprendizagem dos alunos se realiza lentamente, o professor precisa perguntar-se como solucionar esse problema. É preciso utilizar estratégias que possibilitem a todos os alunos da classe um maior número de experiências concretas para que as disciplinas se tornem mais fáceis de serem assimiladas com atividades complementares.

Segundo Mazzotta (1989), as pessoas com deficiência requerem modificações no programa educacional para que possam aprender e desenvolver-se. Portanto, em relação à inclusão, ainda fica difícil essa forma personalizada de ensinar, pois no momento as escolas brasileiras enfrentam salas superlotadas e professores com pouca formação, tornando-se difícil tal atendimento.

Neste contexto, as escolas regulares devem articular-se com o ensino especial, no sentido de obter o suporte necessário para garantir que os alunos com deficiência consigam aprender os conteúdos que o currículo do ensino regular exige. Dessa forma, um dos caminhos possíveis para a construção de uma escola inclusiva, que garanta a aprendizagem 
dos conteúdos a todos os alunos, é o trabalho colaborativo entre professor, a família e outros profissionais da educação.

Pensando na escola como um local fundamentalmente educacional, na qual as ações pedagógicas devem ser implementadas com vistas à promoção da aprendizagem e do desenvolvimento de todos os alunos, é necessário disponibilizar recursos e apoios para atender os diferentes alunos. Trabalhar com um grupo de alunos com diferentes características e trajetórias escolares exige pensar uma aprendizagem de forma diferenciada dos modelos padronizados atuais.

Considerando o processo de inclusão escolar desses alunos como sendo um passo importante para melhoria de sua aprendizagem, acredita-se que isto será possível se forem efetivadas as práticas que respeitem a heterogeneidade desse grupo, sendo o papel do professor, da família, da escola e do governo fundamental neste processo.

Esta pesquisa veio confirmar também que as escolas freqüentadas pelos alunos desse estudo não estão organizando propostas de funcionamento com programas de apoios para dar conta de ensiná-los de da forma adequada. Não basta a escola aceitar a matrícula desses alunos, é preciso garantir boa estrutura e um planejamento que ofereçam alternativas para que consigam progredir na aprendizagem e não somente na socialização, pois, para se socializar, poderão freqüentar até mesmo um clube.

Segundo Mittler (2003, p.36):

A rua de acesso à inclusão não tem um fim porque ela é, em sua essência, mais um processo do que um destino. A inclusão representa, de fato, uma mudança na mente e nos valores para as escolas e para a sociedade como um todo, porque, subjacente à sua filosofia, está aquele aluno ao qual se oferece o que é necessário, e assim, celebra-se a diversidade.

Pensando em um modelo de escola inclusiva que busca proporcionar uma aprendizagem satisfatória e o crescimento global de todos os seus alunos, deverão ser disponibilizados, através de políticas educacionais, mais profissionais capacitados para trabalharem junto aos professores das escolas inclusivas para que seja oferecida uma educação mais individualizada e mediada a esses alunos.

Nesse sentido, o professor necessita adequar suas ações pedagógicas para atender a todos, cabendo então perguntar: "Como um único professor poderá oferecer o ensino individualizado aos alunos com síndrome de Down, se, em sua classe, há no mínimo 38 alunos e todos necessitam aprender igualmente? Como respeitar o ritmo de cada aluno nas 
situações de aprendizagem, se, conforme o constatado, o aluno com síndrome de Down necessita de muito mais tempo para realizar suas atividades?”

Essas perguntas devem ser pesquisadas em outros estudos, pois acredita-se que esta pesquisa tenha atingido o seu objetivo.

Acredita-se que o presente trabalho contribuiu com conhecimentos na área da educação, uma vez que trouxe novos dados em relação à importância da mediação no trabalho com esses alunos para o progresso da aprendizagem escolar e também a possibilidade de reflexões em torno de sua situação escolar e a de alguns professores do Ensino Fundamental e Médio. Isso instiga novos estudos que venham favorecer melhor o processo de inclusão escolar desses alunos, talvez introduzindo novos conceitos diante dessa síndrome.

Portanto, é preciso estruturar melhor as escolas do presente estudo para se tornarem inclusivas, pois estas precisam rever as suas formas de atuação, para melhor oferecer um ensino com eqüidade de modo que adquiram autonomia e sentam-se parte do sistema educacional e social.

Segundo Voivodic (2004) a inclusão não pode continuar a ser vista como uma utopia, não é um modismo e não está ligada apenas às escolas. A inclusão é um processo social maior, que engloba a educação inclusiva, estando vinculada a respeito a direitos humanos.

\title{
THE INCLUSION OF STUDENTS WITH DOWN SYNDROME: A STUDY ON THE EDUCATIONAL SITUATION IN ELEMENTARY AND HIGH SCHOOL IN THE CITY OF ARARAQUARA - SP
}

\begin{abstract}
The present study had the aim to know the scholar situation of the students with Down's Syndrome that attended to the Elementary and Secondary Schools in public and private systems, in the city of Araraquara - SP, referring to the corresponding contents to the grades they were attending. For this purpose a research on the number of these students was made in those mentioned schools at the beginning of the school year of 2006. This study showed that there were 7 students, being five in public schools taking the $2^{\text {nd }}, 3^{\text {rd }}, 4^{\text {th }}, 5^{\text {th }}$ and $6^{\text {th }}$ grades, being one male and four females, having from 14 to 21 years of age and two in private schools, taking the $5^{\text {th }}$ grade of the Elementary school and another taking the $2^{\text {nd }}$ grade of Secondary school, both males and being 17 and 18 years old, respectively. In order to know the scholar trajectory of these students, as well as their situation on the grade they were attending, interviews were held with parents and teachers. The results showed that these students attended special classes for mental deficiency for a period of 3 to 15 years and only after this they were enrolled on the regular school classes, except one of them that hadn't attended special classes. The research showed that these students needed a longer time to accomplish tasks, an individualized teaching, a curricular adaptation, as well as a
\end{abstract}


change on the way of teaching the contents and of dosing even more the amount of activities, in order to avoid the stress.

KEYWORDS: Down's syndrome. Teacher. Public schools. Inclusion.

\section{REFERÊNCIAS}

BRASIL. Ministério da Educação e Cultura. Diretrizes nacionais para a educação especial na educação básica. Brasília, 2001.

Ministério da Justiça. Secretaria de Direitos Humanos. Declaração de Salamanca e linha de ação sobre necessidades educativas especiais. 2. ed. Brasília: CORDE, 1997.

Ministério da Educação e Cultura. Lei no 9.394 de 20 de dezembro de 1996.

Estabelece as diretrizes e bases da educação nacional. Brasília, 1996.

. Casa Civil. Lei n. ${ }^{\circ}$ 8.069/90 de 13 de julho de 1990. Dispõe sobre o Estatuto da

Criança e do Adolescente e dá outras providencias. Brasília, 1990.

Constituição da República Federativa do Brasil: promulgada em 5 de outubro de 1988. Brasília: Imprensa Oficial, 1988.

DUARTE, M. Síndrome de Down: um estudo sobre inclusão escolar na rede pública do ensino fundamental na cidade de Araraquara-SP. 2003. 94f. Dissertação (Mestrado em Educação Escolar) - Faculdade de Ciências e Letras, Universidade Estadual Paulista, Araraquara, 2003.

FLÓREZ, J; TRONCOSO, M. V. Síndrome de Down y educación. 3. ed. Barcelona: Ediciones Científicas y Técnicas, 1994.

MAZZOTTA, M. J. S. Educação escolar: comum ou especial. São Paulo: Pioneira, 1989.

MITTLER, P. Educação inclusiva: contextos sociais. Porto Alegre: Artmed, 2003.

SCHWARTZMAN, J. S. (Org.). Síndrome de Down. São Paulo: Memnon, 1999.

VOIVODIC, M. A. Inclusão escolar de crianças com síndrome de Down. Petrópolis:

Vozes, 2004. 
